\title{
Frailty in patients with interstitial lung disease
}

\author{
Sabina A. Guler ${ }^{\mathrm{a}}$ and Christopher J. Ryerson ${ }^{\mathrm{b}, \mathrm{c}}$
}

\begin{abstract}
Purpose of review
The incidence of age-related diseases such as interstitial lung disease (ILD) is rising, and the importance of multimorbidity and accumulation of health deficits in patients with chronic lung diseases is increasingly recognized. There are multiple relationships between aging and ILD on a demographic and a biological level. Frailty conceptualizes the decline of a patient's physiological reserves and complements the chronological and biological aspects of aging.
\end{abstract}

\section{Recent findings}

Frailty affects more than $50 \%$ of patients with ILD, with respiratory impairment, accelerated biological aging, comorbidities, medication adverse effects, and social factors collectively playing important roles. Frailty is an independent risk factor for adverse health outcomes such as hospitalizations and early mortality, including before and after lung transplant. Given the multicomponent determinants of frailty, programs such as pulmonary rehabilitation are promising strategies for managing this complex issue.

\section{Summary}

Frailty is a common risk factor for adverse outcomes in patients with ILD. The multiple pathways leading to frailty are not completely understood, and further studies are needed to determine the optimal tools for assessment and to develop strategies to prevent and counteract frailty in the aging ILD population.

Keywords

aging, frailty, interstitial lung disease, pulmonary fibrosis

\section{INTRODUCTION}

Interstitial lung disease (ILD) is a group of chronic diseases causing inflammation and/or fibrosis of the lung parenchyma. Patients with ILD suffer from progressive worsening of dyspnea, cough, and pulmonary function, leading to reduced physical performance, quality of life, and early mortality $[1,2]$. The importance of multimorbidity is increasing as people live longer with ILD, and the incidence and prevalence of age-related lung diseases such as chronic obstructive pulmonary disease (COPD), lung cancer, and fibrotic ILDs are rising [3]. As a result, more patients with fibrotic ILD suffer not only the direct consequences of their lung disease, but also from comorbidities and other age-related health deficits $[4,5]$.

Aging is a time-dependent decline in biological and physiological reserves, resulting in an increasing vulnerability to extrinsic biological challenges. Over time, cells, tissues, organs, and individuals lose their resilience and ability to adapt to these stressors [6]. This decline in physiological reserve is encapsulated by the concept of frailty, which differentiates the aspects of functional aging (frailty) from the purely biological and chronological aspects [7]. Patients with chronic diseases frequently have accelerated biological and functional aging due to the accumulation of associated health deficits, but these traits of aging do not always progress continuously or proportionally (Fig. 1) [8]. Many chronic lung diseases, including COPD, lung cancer, and ILD, are age-related diseases with underlying biological hallmarks of aging involved in their pathogenesis [9]. It is thus not surprising that frailty is common in ILD and other chronic lung diseases $\left[10-12,13^{-}\right]$, and is also an independent predictor of poor outcomes in these patients $\left[12,14,15,16^{*}\right]$.

Given the previous findings from populations of patients with severe lung diseases and the biological and demographic relationship between ILDs and aging $[3,9]$, frailty is also increasingly recognized

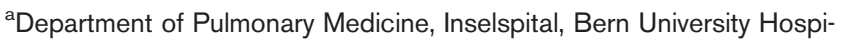
tal, University of Bern, Bern, Switzerland, 'bepartment of Medicine, University of British Columbia and ${ }^{\mathrm{C}}$ Centre for Heart Lung Innovation, St. Paul's Hospital, Vancouver, British Columbia, Canada

Correspondence to Sabina A. Guler, MD, MHSc, Department of Pulmonary Medicine, Inselspital, Bern University Hospital, University of Bern, Freiburgstrasse 18, CH-3010 Bern, Switzerland. Tel: +4131632 80 99; e-mail: sabina.guler@insel.ch

Curr Opin Pulm Med 2020, 26:000-000

DOI:10.1097/MCP.0000000000000692 


\section{KEY POINTS}

- Frailty is the age-related decline of physiological reserves and a measure of functional aging.

- Frequent pulmonary and extrapulmonary deficits result in a high prevalence of frailty in patients with ILD.

- Recent studies demonstrate the importance of frailty as a risk factor for adverse health outcomes in patients with ILD.

- Successful management of frailty likely includes multidisciplinary and multicomponent interventions such as pulmonary rehabilitation.

as an important consideration for patients with ILD. In this review, we summarize the evidence on the impact of frailty and aging in patients with ILD and provide suggestions on how the concept of frailty should be integrated into clinical practice.

\section{FRAILTY IN INTERSTITIAL LUNG DISEASE}

Frailty is present in 3\% of the adult population [17], and $15-22 \%$ of community living elderly people
(>65 years), with prevalence increasing with age and the presence of chronic diseases $[7,8]$. Recent cohort studies demonstrate that approximately half of patients with fibrotic ILD are frail (Table 1) $[5,18]$. There are several potential reasons for this high prevalence, including both direct biological pathways and indirect clinical associations.

\section{Potential direct biological pathways leading to frailty in interstitial lung disease}

Many of the proposed biological pathways of ILD pathogenesis involve mechanisms of accelerated and exaggerated aging $[6,9,23]$. These include mutations in telomerase genes, accelerated telomere attrition, and age-related stem cell exhaustion [24,25], with features of cell senescence more frequently observed in patients with ILD than in COPD [26]. Epigenetic alterations such as downregulation of microRNA expression [27], mitochondrial dysfunction [28], and oxidative stress are further suspected in the pathogenesis of ILDs. Deregulated cellular growth with enhanced Insulin-like growth factor (IGF)-1 signaling might play a role in the pathogenesis of pulmonary fibrosis [29], with IGF-1 being extensively investigated as a blood biomarker of

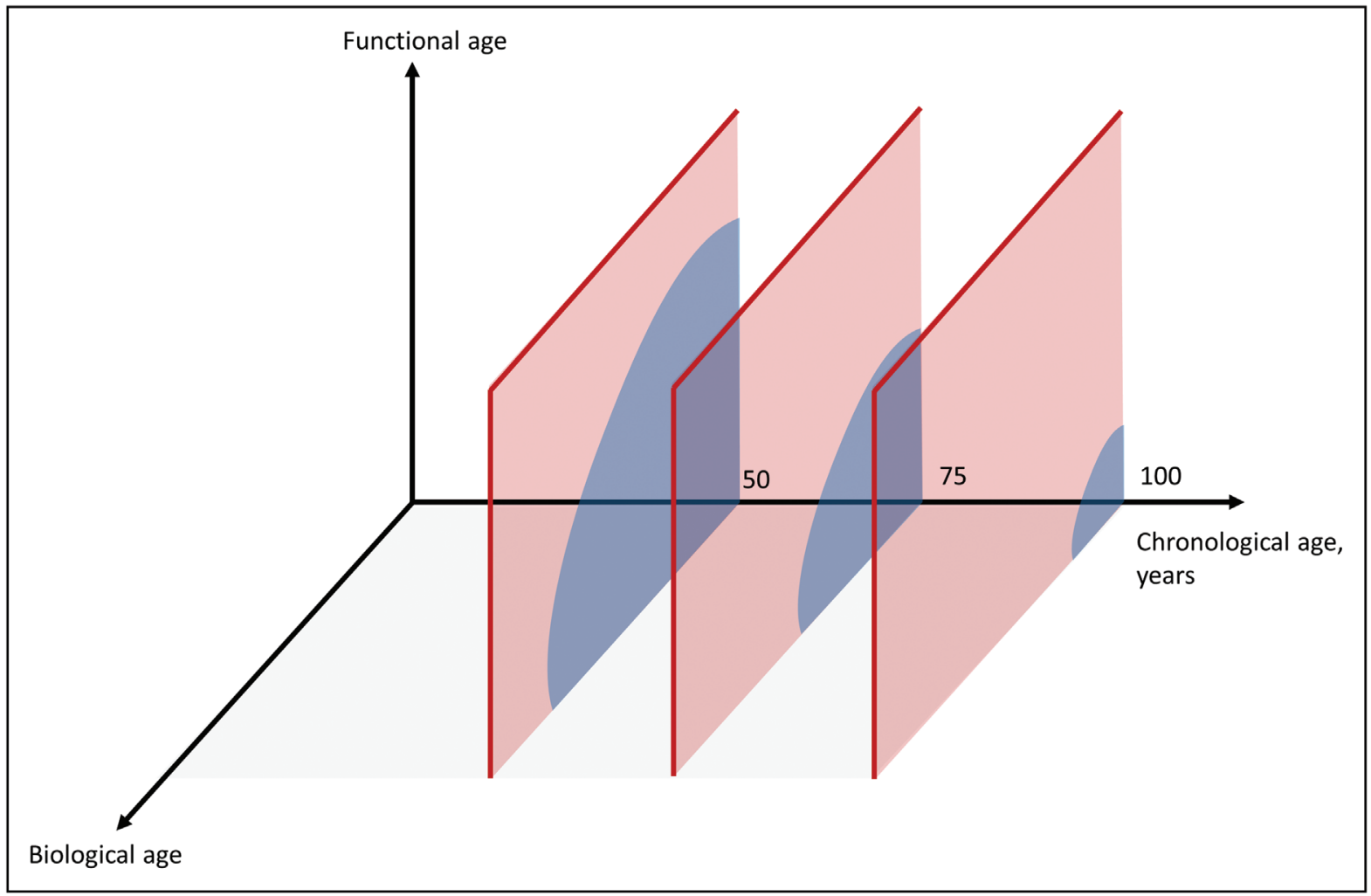

FIGURE 1. Chronological, biological, and functional aging. Over one's lifespan, the rate of increase in biological and functional age varies across individuals. With advancing chronological age, fewer individuals remain biologically and functionally nonfrail (blue), whereas a larger proportion show advanced biological and functional aging consistent with frailty (red). 
Table 1. Prevalence of frailty in patients with interstitial lung disease

\begin{tabular}{|c|c|c|c|c|}
\hline Reference & Included patients & $\begin{array}{l}\text { Frailty assessment } \\
\text { tool }\end{array}$ & $\begin{array}{l}\text { Frailty prevalence } \\
\text { in patients with ILD }\end{array}$ & Other findings \\
\hline Singer et al. ${ }^{a}[12]$ & Patients listed for LTX & $\begin{array}{l}\text { SPPB } \\
\text { FFP }\end{array}$ & $\begin{array}{l}18 / 149(12 \%) \\
61 / 208(29 \%)\end{array}$ & $\begin{array}{l}\text { SPPB and FFP in the complete } \\
\text { cohort is associated with } \\
\text { pretransplant delisting or } \\
\text { death }\end{array}$ \\
\hline Wilson et al. [19] & $\begin{array}{l}\text { Patients with restrictive } \\
\text { lung disease who } \\
\text { underwent LTX }\end{array}$ & $\begin{array}{l}\text { Cumulative frailty index } \\
\text { ( } 32 \text { items) } \\
\text { Frail: } \mathrm{FI} \geq 0.25\end{array}$ & $17 / 46(37 \%)$ & $\begin{array}{l}\text { Frailty in the complete cohort } \\
\text { is associated with higher } \\
\text { risk of mortality after LTX }\end{array}$ \\
\hline Milne et al. ${ }^{a}[5]$ & $\begin{array}{l}\text { Patients with fibrotic ILD } \\
\text { (connective tissue } \\
\text { disease excluded) }\end{array}$ & $\begin{array}{l}\text { Cumulative frailty index } \\
\text { (42 items) } \\
\text { Frail: } \mathrm{FI}>0.21\end{array}$ & $\begin{array}{l}\text { All fibrotic ILD: } \\
\text { 43/86 (50\%) } \\
\text { IPF: } 20 / 41(49 \%)\end{array}$ & $\begin{array}{l}\text { Dyspnea is a more important } \\
\text { predictor of frailty than lung } \\
\text { function }\end{array}$ \\
\hline Guler et al. ${ }^{a}[18]$ & $\begin{array}{l}\text { Patients with systemic } \\
\text { sclerosis associated } \\
\text { ILD }\end{array}$ & $\begin{array}{l}\text { Cumulative frailty index } \\
\text { (42 items) } \\
\text { Frail: } \mathrm{FI}>0.21\end{array}$ & $47 / 86(55 \%)$ & $\begin{array}{l}\text { Dyspnea correlates with the } \\
\text { frailty index }\end{array}$ \\
\hline $\begin{array}{l}\text { Rozenberg } \\
\quad \text { et al. [13-] }\end{array}$ & Patients listed for LTX & FFP & $26 / 80(33 \%)$ & $\begin{array}{l}\text { Good construct validity and } \\
\text { acceptable agreement } \\
\text { among different frailty } \\
\text { indices }\end{array}$ \\
\hline Singer et al. ${ }^{a}\left[16^{\prime \prime}\right]$ & $\begin{array}{l}\text { Patients who underwent } \\
\text { lung transplantation. } \\
\text { Baseline assessment } \\
\text { before LTX }\end{array}$ & $\begin{array}{l}\text { SPPB (primary) } \\
\text { FFP (secondary) }\end{array}$ & $\begin{array}{l}47 / 217(22 \%) \\
70 / 208(34 \%)\end{array}$ & $\begin{array}{l}\text { SPPB and FFP in the complete } \\
\text { cohort is associated with } 1 \text { - } \\
\text { year mortality }\end{array}$ \\
\hline $\begin{array}{l}\text { Venado } \\
\quad \text { et al. }{ }^{a}\left[20^{-}\right]\end{array}$ & Patients undergoing LTX & $\begin{array}{l}\text { SPPB (primary) } \\
\text { FFP (secondary) }\end{array}$ & $\begin{array}{l}42 / 177(24 \%) \\
50 / 121(41 \%)\end{array}$ & $\begin{array}{l}\text { Frailty improves during first } \\
6 \text { months after LTX: SPPB } \\
\begin{array}{l}1.5(95 \% \mathrm{Cl} 1.1-1.8), \text { FFP } \\
-0.9(95 \% \mathrm{Cl}-1.1 \text { to } \\
-0.7)\end{array}\end{array}$ \\
\hline $\begin{array}{l}\text { Sheth et al. } \\
{\left[21^{-1}\right]}\end{array}$ & $\begin{array}{l}\text { Patients with } I P F \geq 65 \\
\text { years }\end{array}$ & $\begin{array}{l}\text { FFP } \\
\text { Frail: score } \geq 3\end{array}$ & Frail $24 / 50(48 \%)$ & $\begin{array}{l}\text { Frailty is associated with } \\
\text { increased age, lower FVC, } \\
\text { DLCO, 6MWD, more severe } \\
\text { fatigue and dyspnea, } \\
\text { greater number of } \\
\text { comorbidities }\end{array}$ \\
\hline $\begin{array}{l}\text { Guler et al. }{ }^{a} \\
\text { [22"] }\end{array}$ & $\begin{array}{l}\text { Patients with fibrotic } \\
\text { ILDs }\end{array}$ & $\begin{array}{l}\text { Cumulative frailty index } \\
\text { (42 items) } \\
\text { Frail: } \mathrm{FI}>0.21\end{array}$ & Frail 272/540 (50\%) & $\begin{array}{l}\text { Frailty is associated with } \\
\text { quality of life, } \\
\text { hospitalizations and survival }\end{array}$ \\
\hline
\end{tabular}

6MWD, 6-min walk distance; $\mathrm{Cl}$, confidence interval; DLCO, diffusing capacity of the lung for carbon monoxide; FFP, Fried frailty phenotype; Fl, frailty index; FVC, forced vital capacity; ILD, interstitial lung disease; IPF, idiopathic pulmonary fibrosis; LTX, lung transplant; SPPB, short physical performance battery.

aPartly overlapping cohorts.

frailty [30"]. Inflammaging, neuroendocrine dysfunction, immunosenescence, and extracellular matrix dysregulation also contribute to the pathogenesis of fibrosis [23]. Cumulatively, these features promote development and progression of pulmonary fibrosis and frailty. The interplay between accelerated biological aging and the clinical syndrome of frailty is not completely understood, but likely involves multiple contributing pathways.

\section{Potential indirect clinical pathways leading to frailty in interstitial lung disease}

Dyspnea and chronic cough are the most frequent pulmonary symptoms in ILD, with dyspnea correlating with the severity of frailty independently of pulmonary function [5]. Extrapulmonary deficits are also frequently present in patients with ILD, including fatigue [31], chronic pain [32], sarcopenia [33"], and weight loss [34]. Approximately 20-40\% of patients with ILD suffer from depression and anxiety [32,35], and these psychological deficits can interfere with social interactions and promote isolation, which then potentially leads to loss of social support and frailty [36,37]. Psychological deficits furthermore might cause physical inactivity [32].

Physical inactivity is an important risk factor for frailty in the general population, with a recent study reporting that individuals spending less time in moderate to vigorous physical activity are more frequently frail 4 years later [38"]. In patients with 
ILD, physical inactivity is likely a major contributor to deconditioning and muscle wasting. Other potential contributors to myopathy in ILD include smoking, chronic inflammation, glucocorticoid medications, oxidative stress, and hormonal disbalances [39]. Frequent changes in body composition, specifically loss of muscle mass, impact physical performance, and potentially cause frailty in patients with ILD $\left[33^{*}, 34\right]$. Frailty is more severe in patients with connective tissue disease (CTD)associated ILD, suggesting that CTD-related extrapulmonary deficits and immunosuppressive medications might also contribute to frailty in these patients $[18,40,41]$.

The importance of recognizing and treating comorbidities in patients with ILD is increasingly evident, with comorbidities impacting the survival of patients $[4,42]$, and substantially contributing to the high economic burden of ILD [43]. Cohort studies including patients with idiopathic pulmonary fibrosis (IPF), and fibrotic hypersensitivity pneumonitis revealed that only 11 and $10 \%$ of patients with IPF and hypersensitivity pneumonitis have no comorbidities, whereas 22 and $30 \%$ have more than four comorbidities, respectively $[4,42]$. In patients with IPF a higher number of comorbidities is associated with increased risk of death, regardless of the specific comorbidity [4]. Some frailty assessment tools include the number and/or type of comorbidities, further illustrating the direct link between these the concepts of frailty and multimorbidity.

\section{ASSESSMENT OF FRAILTY IN INTERSTITIAL LUNG DISEASE}

Most tools used to measure frailty focus on physical aspects, with some multidimensional tools capturing both physical and functional aspects, and some also capturing the presence of multimorbidity. Some frailty assessment tools are useful for the prediction of adverse outcomes [22",44], whereas others are preferably used for the evaluation of interventions $[10,45]$.

The short physical performance battery (SPPB) measures only the physical component of frailty, including usual gait speed (4-m walk test), lower extremity strength (five repetitions sit-to-stand test), and balance tests that are combined in a single score [46]. The Fried frailty phenotype similarly focuses on physical features of frailty, including weight loss, weakness (grip strength), slowness (gait speed), exhaustion, and poor physical activity [45]. Patients are questioned on their level of physical activity, exhaustion, and weight loss, sometimes using more comprehensive questionnaires for these patient-reported items $[10,12]$.
The cumulative Rockwood Frailty Index conceptualizes frailty as a multidimensional syndrome of low physiological reserve that worsens with accumulation of each additional health issue. Typically, between 30 and 70 health-related deficits are assessed, including a variety of symptoms and signs related to independence and selfcare, as well as selfreported diseases and comorbidities. The cumulative Frailty Index is calculated by summing all observed deficits present and dividing them by the number of measured deficits [44]. A Frailty Index more than 0.21 (presence of more than $21 \%$ of the assessed deficits) is used to indicate a frail state, and a Frailty Index of 0.67 is a nonsustainable upper limit where short-term mortality is highly likely $[7,47]$.

It is important to ensure that a frailty assessment tool is appropriate for the intended purpose. There are pros and cons to focusing frailty assessment on the functional versus physical components of frailty in patients with ILD. With the functional Frailty Index measuring deficits across physical, psychological, and social domains, this tool is more comprehensive than the frailty phenotype that solely captures physical impairment. Functional frailty overlaps with comorbidity and disability, whereas sarcopenia, deconditioning, and performance status overlap with physical frailty. The lack of standardization in frailty assessment makes it challenging to compare study results with substantial variability across frailty assessment tools [48].

\section{CONSEQUENCES OF FRAILTY}

Frailty is associated with multimorbidity and increased risk of death at every age in the general population [17], but few studies investigating the impact of frailty in ILD. One recent large study showed that frailty is an independent risk factor for hospitalizations and early mortality in patients with a variety of fibrotic ILD subtypes [22"], and others suggest increased risk of delisting and death before and after lung transplant [12,16"]. It is not clear whether frailty could impact the development or progression of ILD, although frail patients with ILD may be more prone to aspiration, use of medications that can cause or exacerbate ILD, and the detrimental effects of air pollution on pulmonary function [49].

\section{MANAGEMENT OF FRAILTY}

The direct management of frailty is complicated by the presence of several potentially modifiable mechanisms that contribute to its development and progression (Fig. 2). In patients with ILD, frailty is 


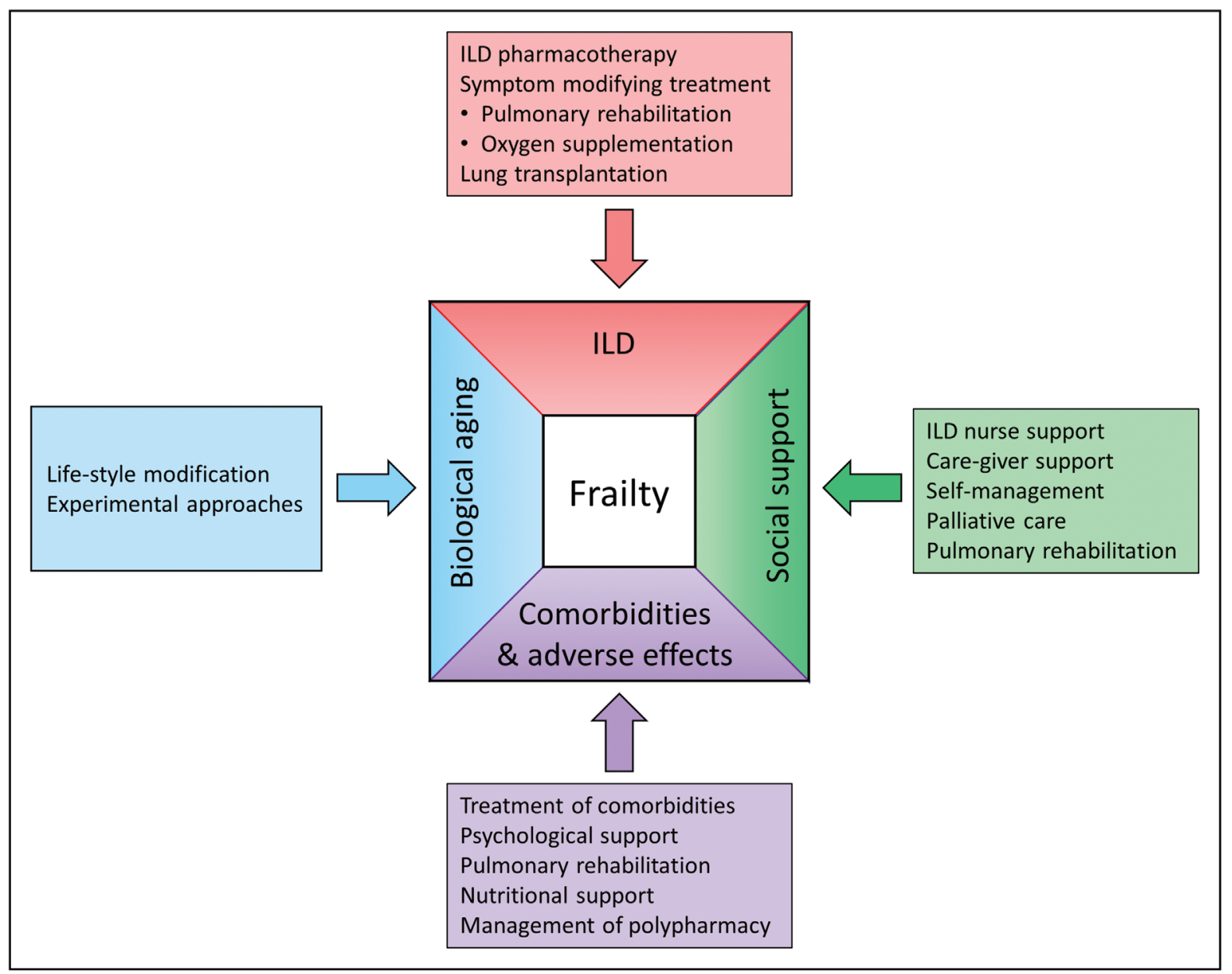

FIGURE 2. Management of frailty in patients with interstitial lung disease. Potential interventions targeting one or several contributing factors of frailty in patients with interstitial lung disease.

primarily impacted by pulmonary function and dyspnea $[5,18]$, and consequently pharmacological treatment that improves or stabilizes ILD severity might indirectly improve frailty in those patients who tolerate these medications well. Conversely, frail patients are likely more susceptible to clinically meaningful adverse effects that could in turn worsen frailty [22"]. For example, while nonfrail patients cope with mild diarrhea as an adverse effect, this might have greater impact on frail patients who lack physiological reserves and coping strategies.

Physical activity is directly associated with biological aging [50], with longer telomeres measured in physically active individuals [51], favorable epigenetic changes with exercise [52], and alleviation of age-related systemic inflammation [53]. Pulmonary rehabilitation improves physical capacity, muscle strength, and dyspnea in patients with ILD, which are key determinants of frailty [54], whereas the nonexercise components of pulmonary rehabilitation (e.g., patient education, self-management) might further improve independence and consequently reduce frailty. However, adherence to pulmonary rehabilitation programs may be more challenging for frail patients [10], suggesting a need for additional support and potentially adjustment of pulmonary rehabilitation programs for frail patients.

Oxygen therapy effectively improves hypoxemia, which is one of the main drivers of dyspnea and low physical performance in patients with ILD. The impact of long-term oxygen therapy (LTOT) on symptoms and exercise performance in patients with ILD remains uncertain, and the relationship between LTOT and frailty has not been investigated. Ambulatory oxygen can be cumbersome and the need to carry oxygen containers might even decrease physical performance and daily physical activity $[55,56]$. Consequently, the potential benefit of LTOT in hypoxemic frail patients needs to be balanced against this additional therapeutic burden.

Comorbidities contribute to frailty in patients with ILD [22"], although their specific management may not always improve frailty given the risk of medication adverse effects and polypharmacy. More 
comprehensive approaches such as diet and exercise are likely to have greater overall impact on frailty. For example, nutritional interventions can improve muscle mass, muscle strength, and physical frailty in older adults [50], and would likely have similar benefits in patients with ILD given the high prevalence and likely prognostic relevance of impaired body composition and weight loss in ILD [33",34]. Finally, lung transplantation is an effective treatment of frailty in selected patients with ILD [20"]. The observed transition from frail to nonfrail in $84 \%$ of the transplanted patients can be explained by the reversal of respiratory limitations as well as the transplant-associated pulmonary rehabilitation and intensified multidisciplinary care.

\section{DISCUSSION}

Frailty is a major health concern in the aging population. Recent studies demonstrate the importance of frailty in ILD; however, important questions regarding the role of frailty in ILD remain.

\section{Is frailty a useful concept for patients with interstitial lung disease?}

A concept that captures the overall health state of patients with ILD is urgently needed. Even though targeted therapy of ILD is necessary to direct specific therapeutic decisions, focusing only on individual deficits (e.g., pulmonary function) might lead to neglect of the overall health state. The overarching concept of frailty is an obvious approach given the importance of comorbidities and extrapulmonary deficits in elderly patients with ILD. In some settings (e.g., prelung transplant), quantification of frailty using an objective and standardized tool can help inform management and triage decisions [57"]. However, additional studies are needed to determine whether objective frailty measurements provide sufficient clinically relevant information to justify the resources required for their measurement, particularly since experienced clinicians intuitively manage patients according to a clinical gestalt that reflects a patient's functional age.

\section{How can frailty be integrated in clinical interstitial lung disease practice?}

There are several clinical scenarios in which frailty assessment might be useful, including treatment allocation, prognostication, and advanced care planning.

Frailty assessment can identify individuals with insufficient reserves to tolerate medication adverse effects [22"], or to cope with surgical complications after diagnostic (e.g., surgical lung biopsy) or therapeutic (e.g., lung cancer resection) procedures. Similarly, frailty can be used to identify ILD patients with an increased risk for poor outcomes, beyond the risk estimated based only on ILD severity [22"]. As an example, frailty may be more valid than chronological age for allocating organs to ILD patients in need of a lung transplantation, and identifies patients who may benefit from 'prehabilitation' before lung transplant $\left[16^{\prime \prime}, 57^{\prime}\right]$. Frailty also provides a framework for discussing treatment goals, and particularly near the end of life in a geriatric population [58]. The International Conference of Frailty and Sarcopenia Research task force recommends screening for frailty in patients 65 years or older, which might result in fewer hospitalizations when frailty is adequately addressed $[59,60]$.

\section{How can we move forward?}

Simple, accurate, and purpose-specific frailty detection tools for clinical practice are needed. The frailty assessment tools most frequently used in research (cumulative Frailty Index, Fried Frailty Phenotype, SPPB) might be too complex for most clinical settings. The Clinical Frailty Scale is a brief physicianadministered tool specifically designed for clinical care [61]. Future research is needed to demonstrate its validity and usefulness for patients with ILD, although the Clinical Frailty Scale may not fully capture the complexity of frailty and more precise measurements may be necessary in some situations. Blood-based biomarkers, potentially involved in pathways linking aging, inflammation, and fibrosis, might be validated for the detection and monitoring of frailty in patients with ILD [30"]. Furthermore, wearable health technology and ecological momentary assessments (frequent real-time sampling of patient experiences in their natural environment) are promising potential methods for frailty detection and quantification $\left[62^{*}, 63\right]$.

The integration of frailty in clinical practice might raise awareness of pitfalls inherent to clinical trials and disease-specific clinical practice guidelines, which are typically relevant to a healthier population who lack multiple comorbidities and health-related deficits [64].

Moving forward, we need to determine if the development and progression of frailty in patients with ILD can be prevented, how frailty can be reversed, and if there is a point of no-return where frailty will progress despite intervention. A homebased exercise training and nutrition intervention supported by a mobile application has been demonstrated to improve physical frailty in lung transplant candidates [62"], and might serve as a model for 
other multicomponent programs addressing frailty in patients with ILD. The common biological pathways of aging and fibrosis also suggest the potential for pharmacological approaches to management of frailty in patients with ILD [65"]. Several of these pathways have been targeted, but without clinically relevant results to date (e.g., treatments related to sex and growth hormones, myostatin, angiotensinconverting enzyme). Further study of these and other approaches is necessary.

\section{CONCLUSION}

The overarching concept of frailty addresses the physical, functional, social, and psychological impairment in patients with ILD. Frailty assessments are not yet widely used for clinical decision making in ILD, and frailty has not been targeted by large clinical trials. Current pharmacological treatment of ILD therefore focuses on pulmonary function; however, there is increasing interest in incorporating quantitative estimates of frailty when deciding on treatments with variable tolerability. Considering the complex nature of frailty and its clear clinical importance, a multidisciplinary care team is likely the ideal approach to management of patients with ILD.

\section{Acknowledgements}

None.

\section{Financial support and sponsorship}

$C . J . R$. has received research funding, grant support, and speaking honoraria from Boehringer Ingelheim and Hoffmann-La Roche. S.A.G. has received grant support and speaking honoraria from Boehringer Ingelheim and Hoffmann-La Roche.

\section{Conflicts of interest}

There are no conflicts of interest.

\section{REFERENCES AND RECOMMENDED \\ READING}

Papers of particular interest, published within the annual period of review, have been highlighted as:

- of special interest

m. of outstanding interest

1. Travis WD, Costabel U, Hansell DM, et al. An official American Thoracic Society/European Respiratory Society statement: update of the international multidisciplinary classification of the idiopathic interstitial pneumonias. Am J Respir Crit Care Med 2013; 188:733-748.

2. Raghu G, Remy-Jardin M, Myers JL, et al. Diagnosis of Idiopathic Pulmonary Fibrosis. An Official ATS/ERS/JRS/ALAT Clinical Practice Guideline. Am J Respir Crit Care Med 2018; 198:e44-e68.

3. Navaratnam V, Fleming KM, West J, et al. The rising incidence of idiopathic pulmonary fibrosis in the U.K. Thorax 2011; 66:462-467.

4. Kreuter M, Ehlers-Tenenbaum S, Palmowski K, et al. Impact of Comorbidities on Mortality in Patients with Idiopathic Pulmonary Fibrosis. PLoS One 2016; 11:e0151425.
5. Milne KM, Kwan JM, Guler S, et al. Frailty is common and strongly associated with dyspnoea severity in fibrotic interstitial lung disease. Respirology 2017; 22:728-734.

6. López-Otín C, Blasco MA, Partridge L, et al. The hallmarks of aging. Cell 2013; 153:1194-1217.

7. Rockwood K, Song X, Mitnitski A. Changes in relative fitness and frailty across the adult lifespan: evidence from the Canadian National Population Health Survey. CMAJ 2011; 183:E487-E494.

8. Bandeen-Roche K, Seplaki CL, Huang J, et al. Frailty in older adults: a nationally representative profile in the United States. J Gerontol A Biol Sci Med Sci 2015; 70:1427-1434.

9. Selman $M$, Pardo $A$. Revealing the pathogenic and aging-related mechanisms of the enigmatic idiopathic pulmonary fibrosis. An integral model. Am J Respir Crit Care Med 2014; 189:1161-1172.

10. Maddocks M, Kon SS, Canavan JL, et al. Physical frailty and pulmonary rehabilitation in COPD: a prospective cohort study. Thorax 2016; 71:988-995.

11. Park SK, Richardson CR, Holleman RG, et al. Frailty in people with COPD, using the National Health and Nutrition Evaluation Survey dataset (20032006). Heart Lung 2013; 42:163-170.

12. Singer JP, Diamond JM, Gries CJ, et al. Frailty phenotypes, disability, and outcomes in adult candidates for lung transplantation. Am J Respir Crit Care Med 2015; 192:1325-1334.

13. Rozenberg D, Mathur $S$, Wickerson $L$, et al. Frailty and clinical benefits with - lung transplantation. J Heart Lung Transplant 2018; 37:1245-1253.

The study prospectively evaluated the construct validity of the Fried frailty phenotype in 50 lung transplant candidates, including 32 patients with interstitial lung disease (ILD). In a retrospective dataset including 80 ILD patients, the group found no significant differences between frail and nonfrail patients for in-hospital mortality, length of hospital stay, and 1-year mortality after lung transplantation. Frail patients had larger improvement in health-related quality of life and 6-min walk distance following transplant compared with nonfrail patients.

14. Galizia G, Cacciatore F, Testa G, et al. Role of clinical frailty on long-term mortality of elderly subjects with and without chronic obstructive pulmonary disease. Aging Clin Exp Res 2011; 23:118-125.

15. Lahousse L, Ziere G, Verlinden VJ, et al. Risk of frailty in elderly with COPD: a population-based study. J Gerontol A Biol Sci Med Sci 2016; 71:689-695.

16. Singer JP, Diamond JM, Anderson MR, et al. Frailty phenotypes and mortality

- after lung transplantation: a prospective cohort study. Am J Transplant 2018; 18:1995-2004

The multicenter prospective cohort study analyzed frailty using two separate frailty tools in more than 300 patients listed for lung transplantation, including approximately 200 patients with ILD. There was a statistically significant association between pretransplant frailty assessed by the short physical performance battery and 1 and 4-year mortality after lung transplantation [adjusted hazard ratio (HR) 7.5; 95\% confidence interval $(\mathrm{Cl}) 1.6-36$ and $3.8 ; 95 \% \mathrm{Cl}: 1.8-8$, respectively]. Furthermore, frail patients defined using the Fried Frailty phenotype had a higher risk of death within the first year after lung transplantation (adjusted HR 3.8; 95\% Cl: $1.1-13.2)$, but not after 4 years.

17. Hanlon $\mathrm{P}$, Nicholl $\mathrm{BI}$, Jani $\mathrm{BD}$, et al. Frailty and prefrailty in middle-aged and older adults and its association with multimorbidity and mortality: a prospective analysis of 493737 UK Biobank participants. Lancet Public Health 2018; 3:e323-e332.

18. Guler $\mathrm{SA}, \mathrm{Kwan} J \mathrm{M}$, Winstone TA, et al. Severity and features of frailty in systemic sclerosis-associated interstitial lung disease. Respir Med 2017; 129:1-7.

19. Wilson ME, Vakil AP, Kandel $P$, et al. Pretransplant frailty is associated with decreased survival after lung transplantation. J Heart Lung Transplant 2016; 35:173-178.

20. Venado A, McCulloch C, Greenland JR, et al. Frailty trajectories in adult lung - transplantation: a cohort study. J Heart Lung Transplant 2019; 38:699-707. The cohort included 246 patients who survived the first 6 months after lung transplantation, including 177 ILD patients. Frailty improved in the first 6 months after lung transplantation and remained stable up to 3 years after transplant. $84 \%$ of patients who were frail before lung transplant became nonfrail after transplant. Frailty in patients with ILD improved to a similar extent compared with patients with chronic obstructive pulmonary disease.

21. Sheth JS, Xia M, Murray S, et al. Frailty and geriatric conditions in older - patients with idiopathic pulmonary fibrosis. Respir Med 2019; 148:6-12. The prospective cohort study applied the Fried frailty phenotype to 50 patients with idiopathic pulmonary fibrosis (IPF) over the age of 65 years and found that $48 \%$ of participants were frail, and that frailty was associated with fatigue, diffusion capacity of the lung for carbon monoxide, and pectoralis muscle mass.

22. Guler SA, Kwan JM, Leung JM, et al. Functional ageing in fibrotic interstitial - lung disease: the impact of frailty on adverse health outcomes. Eur Respir J 2020; 55:1900647.

This is the first prospective cohort study evaluating the impact of frailty on several adverse health outcomes in ILD. In 540 patients with a variety of fibrotic ILDs (including 100 patients with IPF), frailty was associated with mortality, frequency of hospitalizations, length of hospital stay, and health-related quality of life, with all findings being independent of age, sex, disease severity, and an IPF diagnosis. Additional analyses suggested that frail patients may also suffer more frequently from medication adverse reactions. 
23. Meiners $S$, Eickelberg $O$, Königshoff $M$. Hallmarks of the ageing lung. Eur Respir J 2015; 45:807-827.

24. Snetselaar $\mathrm{R}$, van Moorsel $\mathrm{CHM}$, Kazemier KM, et al. Telomere length in interstitial lung diseases. Chest 2015; 148:1011-1018.

25. Chilosi M, Doglioni $C$, Murer $B$, et al. Epithelial stem cell exhaustion in the pathogenesis of idiopathic pulmonary fibrosis. Sarcoidosis Vasc Diffuse Lung Dis 2010; 27:7-18.

26. Okuda R, Aoshiba $K$, Matsushima $H$, et al. Cellular senescence and senescence-associated secretory phenotype: comparison of idiopathic pulmonary fibrosis, connective tissue disease-associated interstitial lung disease, and chronic obstructive pulmonary disease. J Thorac Dis 2019; 11:857-864.

27. Dakhlallah $D$, Batte $K$, Wang $Y$, et al. Epigenetic regulation of miR-17 92 contributes to the pathogenesis of pulmonary fibrosis. Am J Respir Crit Care Med 2013; 187:397-405.

28. Roque W, Cuevas-Mora $K$, Romero F. Mitochondrial quality control in agerelated pulmonary fibrosis. Int J Mol Sci 2020; 21:643. doi:10.3390/ ijms21020643.

29. Choi JE, Lee SS, Sunde DA, et al. Insulin-like growth factor-I receptor blockade improves outcome in mouse model of lung injury. Am J Respir Crit Care Med 2009; 179:212-219.

30. Cardoso AL, Fernandes A, Aguilar-Pimentel JA, et al. Towards frailty biomar-

- kers: candidates from genes and pathways regulated in aging and age-related diseases. Ageing Res Rev 2018; 47:214-277.

The systemic review and search of gene expression databases identifies potential frailty biomarkers by investigating genes and pathways related to aging and agerelated diseases. Potential biomarkers are categorized according to priority and involvement in distinct pathways of aging.

31. Atkins $C P$, Gilbert $D$, Brockwell $C$, et al. Fatigue in sarcoidosis and idiopathic pulmonary fibrosis: differences in character and severity between diseases. Sarcoidosis Vasc Diffuse Lung Dis 2016; 33:130-138.

32. Hur SA, Guler SA, Khalil N, et al. Impact of psychological deficits and pain on physical activity of patients with interstitial lung disease. Lung 2019; 197:415-425

33. Guler SA, Hur SA, Lear SA, et al. Body composition, muscle function, and

- physical performance in fibrotic interstitial lung disease: a prospective cohort study. Respir Res 2019; 20:56.

The cohort study investigates the significance of sarcopenia in 115 patients with fibrotic ILD, showing that low muscle mass, weak grip strength, and slow gait speed all correlate with ILD severity.

34. Nakatsuka $Y$, Handa $T$, Kokosi $M$, et al. The clinical significance of body weight loss in idiopathic pulmonary fibrosis patients. Respiration 2018; 96: 338-347.

35. Glaspole IN, Watson AL, Allan $\mathrm{H}$, et al. Determinants and outcomes of prolonged anxiety and depression in idiopathic pulmonary fibrosis. Eur Respir J 2017; 50:1700168. Published 2017 Aug 17. doi:10.1183/13993003. 00168-2017.

36. Swigris JJ, Stewart AL, Gould MK, et al. Patients' perspectives on how idiopathic pulmonary fibrosis affects the quality of their lives. Health Qual Life Outcomes 2005; 3:61.

37. Gale CR, Westbury L, Cooper C. Social isolation and loneliness as risk factors for the progression of frailty: the English Longitudinal Study of Ageing. Age Ageing 2018; 47:392-397.

38. Mañas A, Del Pozo-Cruz B, Rodríguez-Gómez l, et al. Which one came first:

- movement behavior or frailty? A cross-lagged panel model in the Toledo Study for Healthy Aging. J Cachexia Sarcopenia Muscle 2020; 11:415-423.

The population-based longitudinal cohort study included 186 participants over the age of 65 years. Individuals who spend less time in moderate-to-vigorous physical activity were more likely to have an increase in their frailty score 4 years later. The authors suggest promotion of physical activity can prevent frailty in older adults.

39. Guadalupe-Grau A, Carnicero JA, Losa-Reyna J, et al. Endocrinology of aging from a muscle function point of view: results from the Toledo Study for Healthy Aging. J Am Med Dir Assoc 2016; 18:234-239.

40. Gutiérrez-Valencia $M$, Izquierdo $M$, Cesari $M$, et al. The relationship between frailty and polypharmacy in older people: a systematic review. $\mathrm{Br} \mathrm{J}$ Clin Pharmacol 2018; 84:1432-1444.

41. Haider S, Grabovac I, Berner C, et al. Frailty in seropositive rheumatoid arthritis patients of working age: a cross-sectional study. Clin Exp Rheumatol 2019; 37:585-592.

42. Wälscher J, Gross B, Morisset J, et al. Comorbidities and survival in patients with chronic hypersensitivity pneumonitis. Respir Res 2020; 21:12.

43. Frank AL, Kreuter M, Schwarzkopf L. Economic burden of incident interstitial lung disease (ILD) and the impact of comorbidity on costs of care. Respir Med $2019 ; 152: 25-31$
44. Mitnitski AB, Mogilner AJ, Rockwood K. Accumulation of deficits as a proxy measure of aging. ScientificWorldJournal 2001; 1:323-336.

45. Fried LP, Tangen $\mathrm{CM}$, Walston J, et al. Frailty in older adults: evidence for a phenotype. J Gerontol A Biol Sci Med Sci 2001; 56:M146-M156.

46. Guralnik JM, Simonsick EM, Ferrucci L, et al. A short physical performance battery assessing lower extremity function: association with self-reported disability and prediction of mortality and nursing home admission. J Gerontol 1994; 49:M85-M94.

47. Rockwood K, Mitnitski A. Limits to deficit accumulation in elderly people. Mech Ageing Dev 2006; 127:494-496.

48. Aguayo GA, Donneau AF, Vaillant MT, et al. Agreement between 35 published frailty scores in the general population. Am J Epidemiol 2017; 186:420-434.

49. Eckel SP, Louis TA, Chaves PH, et al. Modification of the association between ambient air pollution and lung function by frailty status among older adults in the Cardiovascular Health Study. Am J Epidemiol 2012; 176:214-223.

50. Bauer JM, Verlaan S, Bautmans $I$, et al. Effects of a vitamin $D$ and leucineenriched whey protein nutritional supplement on measures of sarcopenia in older adults, the PROVIDE study: a randomized, double-blind, placebocontrolled trial. J Am Med Dir Assoc 2015; 16:740-747.

51. Latifovic L, Peacock SD, Massey TE, et al. The influence of alcohol consumption, cigarette smoking, and physical activity on leukocyte telomere length. Cancer Epidemiol Biomarkers Prev 2016; 25:374-380.

52. Ferioli $M$, Zauli G, Maiorano $P$, et al. Role of physical exercise in the regulation of epigenetic mechanisms in inflammation, cancer, neurodegenerative diseases, and aging process [published online ahead of print, 2019 Feb 14]. J Cell Physiol 2019; 10.1002/jcp.28304. doi:10.1002/jcp.28304.

53. Lavin KM, Perkins RK, Jemiolo $B$, et al. Effects of aging and lifelong aerobic exercise on basal and exercise-induced inflammation. J Appl Physiol 2020; 128:87-99.

54. Perez-Bogerd S, Wuyts W, Barbier V, et al. Short and long-term effects of pulmonary rehabilitation in interstitial lung diseases: a randomised controlled trial. Respir Res 2018; 19:182.

55. Ramadurai $D$, Riordan $M$, Graney B, et al. The impact of carrying supplemental oxygen on exercise capacity and dyspnea in patients with interstitial lung disease. Respir Med 2018; 138:32-37.

56. Khor $\mathrm{YH}$, Holland $\mathrm{AE}$, Goh NS, et al. Ambulatory oxygen in fibrotic interstitial lung disease: a pilot, randomized, triple-blinded, sham-controlled trial. Chest 2020.

57. Kobashigawa J, Dadhania D, Bhorade $S$, et al. Report from the American

- Society of Transplantation on frailty in solid organ transplantation. Am J Transplant 2019; 19:984-994.

The consensus conference report on solid organ transplantation highlights the importance of frailty in lung transplantation. A survey of 56 lung transplant physicians demonstrated that the majority think frailty is a useful concept in this setting, with more than half performing formal frailty assessments in their patients, and $85 \%$ stating that frailty status should influence decisions on timing of lung transplantation.

58. Stow D, Matthews FE, Hanratty B. Frailty trajectories to identify end of life: a longitudinal population-based study. BMC Med 2018; 16:171.

59. Dent E, Morley JE, Cruz-Jentoft AJ, et al. Physical frailty: ICFSR international clinical practice guidelines for identification and management. J Nutr Health Aging 2019; 23:771-787.

60. McGrath J, Almeida P, Law R. The Whittington Frailty Pathway: improving access to comprehensive geriatric assessment: an interdisciplinary quality improvement project. BMJ Open Qual 2019; 8:e000798.

61. Rockwood $K$, Song $X$, MacKnight $C$, et al. A global clinical measure of fitness and frailty in elderly people. CMAJ 2005; 173:489-495.

62. Singer JP, Soong A, Bruun A, et al. A mobile health technology enabled home-

- based intervention to treat frailty in adult lung transplant candidates: a pilot study. Clin Transplant 2018; 32:e13274.

The interventional pilot study demonstrated the feasibility of a home-based rehabilitation program that included a mobile device application for frail lung transplant candidates. There was a trend toward frailty improvement in the 13 patients who completed the program.

63. Dunton GF. Ecological momentary assessment in physical activity research. Exerc Sport Sci Rev 2017; 45:48-54.

64. Boyd CM, Darer J, Boult C, et al. Clinical practice guidelines and quality of care for older patients with multiple comorbid diseases: implications for pay for performance. JAMA 2005; 294:716-724.

65. Merkt W, Bueno M, Mora AL, et al. Senotherapeutics: targeting senescence in - idiopathic pulmonary fibrosis. Semin Cell Dev Biol 2019; 101:104-110. The recent review summarizes the current evidence on the hallmarks of aging in IPF, and discusses potential future treatment strategies for IPF that target cellular senescence. 